\title{
Cordonnier Grade 3 Fungal Complication, Candidemia with Either Sepsis or Deep
}

\section{Focus}

National Cancer Institute

\section{Source}

National Cancer Institute. Cordonnier Grade 3 Fungal Complication, Candidemia with

Either Sepsis or Deep Focus. NCI Thesaurus. Code C138302.

Any candidemia with either sepsis or deep focus. 